\title{
A ESCRITA DE PROFESSORAS NOS MEMORIAIS DE FORMAÇÃO
}

MARIA COUTO CUNHA

Universidade Federal da Bahia

MARTA LÍCIA BRITO DE JESUS

Universidade Federal da Bahia

REGINA LUCIA PORTELA

Universidade Federal da Bahia

Este artigo discute as produções textuais dos Memoriais de Formação escritos por professoras de escolas públicas, que fizeram o curso de Licenciatura Especial em Pedagogia, na Faculdade de Educação da Universidade Federal da Bahia (FACED/UFBA), entre 2010 e 2013, no contexto do Plano Nacional de Formação de Professores da Educação Básica (PARFOR). Do ponto de vista teórico-metodológico, referencia-se nas ideias de Kofes (2015), a respeito das narrativas etnográficas e traz uma pesquisa documental, de cunho qualitativo, amparada nos pressupostos da Análise do Discurso (ORLANDI; 2002; 2003; 2004), com ênfase nos estudos sobre autobiografia e educação (JOSSO, 2002; 2007; SOUZA, 2007; 2011). Foram analisados os memoriais de 18 professoras, apresentados nos respectivos Trabalhos de Conclusão de Curso (TCC). Conclui-se a discussão com evidências sobre a apropriação pelas professoras desse espaço de valorização das narrativas, através de uma escrita autoral e prenhe de conteúdos considerados significativos, relacionados à identidade profissional e a suas histórias de vida.

Palavras-chave: Formação de Professores. Memoriais de Formação. Narrativa.

\section{ABSTRACT THE TEACHER'S WRITING IN THE TRAINING MEMORIALS}

This article discusses textual productions of training memorials written by public school teachers who enrolled in the Special Graduate course in Pedagogy at the Faculty of Education of the Federal University of Bahia (FACED/UFBA) between 2010 and 2013 in the context of the National Plan for the Training of Basic Education Teachers (PAR- 
FOR). From a theoretical and methodological point of view, this article is referenced in ideas about ethnographic narratives Kofes (2015) in the qualitative documental research based on the assumptions of the analysis of discourse (ORLANDI, 2002, 2003 e 2004) and in the studies on autobiography and education (JOSSO, 2002, 2007; SOU$Z A, 2007,2011)$. The training memorials of 18 teachers, presented in their respective Course Completion Work (TCC), were analyzed. This discussion is concluded with evidences on the appropriation by the teachers of this space of appreciation of the narratives, through an authorial writing, filled with contents considered significant and that are related to their professional identity and life histories.

Keywords: Teachers Training. Training Memorials. Narrative.

\section{RESUMEN LA ESCRITURA DE PROFESORAS EN LOS MEMORIALES DE FORMACIÓN}

Este artículo discute las producciones textuales de los memoriales de formación escritos por profesoras de escuelas públicas que hicieron el curso de Licenciatura Especial en Pedagogía en la Facultad de Educación de la Universidad Federal de la Bahía (FACED/UFBA), entre 2010 y 2013, en el contexto del Plan Nacional de Formación de Profesores de la Educación Básica (PARFOR). Desde el punto de vista teórico-metodológico, se referencia en Kofes (2105) respecto de las narrativas etnográficas y traza una investigación documental de carácter cualitativo amparada en los presupuestos de análisis del discurso (ORLANDI, 2002, 2003 e 2004), la autobiografía y la educación (JOSSO, 2002, 2007; SOUZA, 2007, 2011). Fueron analizados los memoriales de formación de 18 profesoras, presentados en los respectivos Trabajos de Conclusión de Curso (TCC). Se concluye la discusión con evidencias sobre la apropiación por las profesoras de ese espacio de valorización de las narrativas, a través de un escrito autoral y lleno de contenidos considerados significativos relacionados a la identidad profesional y a sus historias de vida.

Palabras clave: Formación de profesores. Memoriales de Formación. Narrativa.

\section{Memória, narrativa, experiência e discurso na escrita de professoras}

- A vida, Senhor Visconde, é um pisca-pisca. A gente nasce, isto é, começa a piscar. Quem para de piscar chegou ao fim, morreu. Piscar é abrir e fechar os olhos - viver é isso. É um dorme e acorda, dorme e acorda, até que dorme e não acorda mais. [...] A vida das gentes neste mundo, senhor sabugo, é isso. Um rosário de piscados. Cada pisco é um dia. Pisca e mama: pisca 
e brinca; pisca e estuda; pisca e ama; pisca e cria filhos; pisca e geme os reumatismos; por fim pisca pela última vez e morre.

- E depois que morre? - Perguntou o Visconde. - Depois que morre, vira hipótese. É ou não é? 0 Visconde teve de concordar que era. (LOBATO, 1995, p. 9)

A lembrança dos diálogos entre os personagens Emília e o Visconde de Sabugosa, do Sítio do Pica-pau Amarelo, de autoria de Monteiro Lobato, sobre a necessidade de Emília escrever um livro contendo suas memórias, além de ser muito divertida, nos dá pistas sobre algo que já se sabe: a complexidade que é o registro de recordações vividas por alguém na "vida real".

A construção da memória, segundo Pollak (1992), que faz essa discussão no campo da História, é formada por elementos que são experimentados pelo grupo ao qual a pessoa tem um sentimento de pertencimento, denominado pelo autor de acontecimentos, lugares e personagens vividos por tabela, que podem ou não ter pertencido ao espaço-tempo da pessoa. Por exemplo, a data real em que a vivência ocorre não é o mais importante, visto que as lembranças são desobedientes à ideia de um tempo cronológico e organizado. As lembranças nos permitem percorrer questões que são mais importantes pelo seu significado da memória, que está sendo revelado nas suas diversas nuanças, ora ligado à vida privada, ora à vida pública do autor.

A memória, como capacidade de conservar certas informações que o homem pode ressignificar de impressões passadas (LE GOFF, 2000), está ligada ao grupo social de pertencimento da rede de relações sociais da qual fazemos parte. Essa capacidade do sujeito de reinventar o vivido revela um processo em que é possivel identificar, nas repetições de sua experiência, tal como as piscadelas de Emília, as várias interpretações acerca dos novos acontecimentos que produzem sentido ao seu pre- sente. Para Pollak (1992), é nesse movimento que reside a existência de uma ligação estreita entre a memória e a identidade social dos sujeitos (imagem de si, para si e para os outros), o que, por sua vez, garante o sentimento de continuidade e coerência de uma pessoa como parte de um grupo em permanente construção.

As formulações de Le Goff (2000) e Pollak (1992) vão ao encontro do que afirma Pêcheux (1999) acerca da memória discursiva, posto que, na materialidade dos discursos, evidencia-se não a recordação de acontecimentos recuperados de algo distante do passado de cada um, mas acontecimentos mobilizados e manifestos discursivamente pelos sujeitos, de forma dinâmica, e observados na repetição e na regularidade dos sentidos atribuídos a uma memória construída em rede e em permanente processo de interpretação ocorrido no presente.

A abordagem da memória a partir da ressignificação da História de Vida das professoras em uma situação específica de tornar pública uma autobiografia, através de um Trabalho de Conclusão de Curso (TCC), aqui denominado como Memoriais de Formação, sem dúvida nos remete às situações educativas envolvidas neste trabalho, porque tais situações permitem dar pistas acerca das representações do saber-fazer docente e dos referenciais que servem para descrever e compreender-se a si próprio e ao outro como experiências formadoras.

Assim, durante a investigação sobre os Memoriais de Formação, o foco da análise foi compreender os discursos produzidos pelas professoras como uma categoria profissional, ou melhor, como um grupo social de pertencimento do qual as docentes fazem parte. Mesmo com o encantamento inicial provocado pelo contato com a dimensão pessoal das memórias explicitadas nas narrativas, a tentativa foi interpretar os olhares particulares, em uma 
rede de relações sociais dinâmicas, envolvendo o grupo de professoras em formação.

Walter Benjamin (1994), em seu texto clássico $O$ narrador, identifica o irremediável fim das "narrativas tradicionais" com o início do capitalismo e o surgimento de comportamentos imediatistas, por parte de uma sociedade ávida por informações rápidas e efêmeras, que se esvaem em si mesmas. O autor considera fundamental implicar-se na instigante articulação entre o sujeito, a linguagem e a contemporaneidade, em uma experiência com narrativas.

Segundo Benjamin (1994), as narrativas sempre vão tratar de uma experiência que traz como substrato a dimensão do narrador enquanto protagonista de um fato histórico social localizado, pois provocam a reflexão, o espanto e nunca se exaurem, caracterizandose pelo relato de uma existência que, ao ser narrada para o outro, evidencia em si uma essência única, visto que "seu dom é poder contar sua vida; sua dignidade é contá-la inteira" (BENJAMIN, 1994, p. 221).

Diante do exposto, entendemos que resgatar a narrativa das professoras nos Memoriais de Formação para um Trabalho de Conclusão de Curso de Licenciatura em Pedagogia do PARFOR, em uma pesquisa, pode significar uma aproximação com as "narrativas tradicionais" apresentadas por Benjamin, evidenciando o sentido da coletividade, na troca de experiências, a partir de relatos de uma vivência formativa, na qual as professoras colocam-se como autoras de um trabalho de reconstituição e reflexão da própria existência identitária, como docentes, por meio da escrita.

A escrita configura-se, também, como um instrumento avaliativo precioso, por possibilitar ao professor memorialista a análise crítica da relação teoria-prática, no âmbito do seu trabalho, demonstrando o sentido da formação, momento em que se torna possivel des- construir conceitos cristalizados de um fazer, por vezes mecânico e desprovido de criticidade, possibilitando ampliar o corpus da experiência pessoal e social que tem lugar dentro e fora da escola.

Pode-se conceber esse caminho de pesquisar os memoriais do curso de Pedagogia PARFOR como inscrito em um espaço no qual as professoras evocam a experiência de si, questionam os sentidos das suas vivências e aprendizagens, revisitam conceitos mobilizados no Curso, ressignificam valores, atitudes e práticas, reconstroem identidades e, portanto, ensinam e aprendem, a partir da ação de compartilhar suas reflexões sobre o vivido.

Nessa perspectiva, destaca-se uma contribuição importante para os estudos sobre os professores e as escritas de si, no âmbito das abordagens autobiográficas:

A abordagem biográfico-narrativa assume a complexidade e a dificuldade em atribuir primazia ao sujeito ou à cultura no processo de construção de sentido. Ao longo de seu percurso pessoal, consciente de suas idiossincrasias, o indivíduo constrói sua identidade pessoal mobilizando referentes que estão no coletivo. Mas, ao manipular esses referentes de forma pessoal e única, constrói subjetividades, também únicas. (SOUZA, 2007, p. 65)

$\mathrm{Na}$ ideia defendida anteriormente, a noção de experiência mostrou-se como sendo de fundamental importância neste trabalho investigativo, visto que os anos vividos pelas professoras no exercício da profissão reverberam em suas produções discursivas, aflorando um saber-fazer docente mobilizado pelo coletivo do qual fazem parte. Abordar a experiência das professoras através dos discursos evidenciados nos Memoriais de Formação, remete-nos às ideias de Kofes (2015) que, ao trazer à baila uma importante discussão teórico-metodológica sobre o lugar das narrativas biográficas na caminhada da Antropologia, levanta um aspecto indispensável para orientar o tra- 
balho com relatos de vida: a defesa de que é possivel não só tomar as biografias e autobiografias como objeto, mas reinventá-las a partir da construção de um novo marco conceitual, o qual autoriza a apropriação da intenção autobiográfica como uma narrativa etnográfica.

Isso quer dizer que a análise dos memoriais deve ser feita à luz de uma interpretação e análise dos relatos de experiência, conjugando a descrição dessa experiência narrada com a carga de reflexividade envolvida no registro. Diante da complexidade que as narrativas anunciam, é que a Análise do Discurso (AD) se mostrou coerente para inspirar o percurso deste trabalho, justamente por não se tratar de uma tradução de um discurso que se produz fora do sujeito, e sim da interpretação da produção de sentidos que são mediados pela ideologia, pela História e pela linguagem de quem narra e, portanto, são prenhes dos modos de ser e de agir, no contexto vivido, discursivamente, na dinâmica dos sujeitos.

A dinâmica na $A D$ pode ser interpretada, neste artigo, através de diferentes dispositivos, entre os quais se destacam a formação discursiva, ou melhor, a posição social ocupada pelas professoras em formação; a formação ideológica compreendida como o contexto provocado por essa posição social, na formação dos discursos presentes na escrita dos memoriais, e o interdiscurso que se mostra entre o dito e o não dito, no ato do sujeito rememorar suas experiências.

A longa tradição da $A D$, na qual nos inspiramos, tem sua origem na França, a partir da década de sessenta do século passado, com as sinteses conceituais produzidas pelo pensamento de Pêcheux (1999). Essa tradição, aqui no Brasil, se apresenta com muita intensidade nas obras de Orlandi (2002; 2003; 2004), pesquisadora que há mais de quarenta anos nos provoca a reconhecer, nos pressupostos da $A D$, uma potencialidade para a interpretação de evidências produzidas nas marcas da materialidade discursiva, construídas historicamente pelos sujeitos.

Pelo tempo de reflexão acerca da produção da $A D$, foram percebidas diversas mudanças conceituais desde o seu surgimento, quando da definição das bases responsáveis pela delimitação do campo de investigação. Através desse campo, surge um jeito inédito de tratar o discurso como "objeto" de teoria. As mudanças, dessa forma particular de compreender teoricamente os discursos, abarcam uma configuração atual dos desafios postos pela AD para o desenvolvimento de nossas análises.

Os desafios são assumidos da seguinte forma: a necessidade de adotar uma postura metodológica que seja capaz de interpretar o assujeitamento ideológico dos discursos produzidos pelos sujeitos em relação à exterioridade dos acontecimentos sociais dos quais eles participam ativamente. Tal postura implicou na mudança do próprio conceito de sujeito, já que abriga um "nós" dentro dele e não um "eu" autocentrado. Outra mudança significou a ampliação da noção de discurso, em virtude de que há diversas possibilidades de materialidade das manifestações desses sujeitos.

Ainda na perspectiva teórico-metodológica, é importante estabelecer uma clara distinção entre observar e ouvir narrativas. Foi possivel perceber a maneira como cada professora teceu reflexões sobre as suas trajetórias, circunscritas ao âmbito da escrita memorialística, em detrimento da observação da caminhada delas em si. 0 documento escrito é o foco da análise, e tem uma singularidade como gênero textual.

Do ponto de vista das implicações com a produção do documento em si, elas são muitas e convém esclarecer que o acesso não se deu apenas ao resultado da produção, visto que, direta e indiretamente, mesmo não sendo orientadoras dos TCC analisados, na condição 
de ex-professoras e membros da Coordenação do Curso, foi possivel acompanhar os bastidores da escrita dessa produção. Sem dúvida, essa posição privilegiada, enquanto os memoriais estavam sendo construídos, forneceu as ferramentas para compreendermos um pouco mais de perto a inteireza do que estava sendo selecionado como conteúdo do discurso mobilizado pelas professoras-alunas na produção escrita, bem como as emoções e a lógica presentes nas escolhas das temáticas trabalhadas, já que se conheciam os personagens em "carne e osso".

\section{A pesquisa sobre os memoriais de formação das professoras}

Uma breve revisão de literatura indica ser crescente o interesse dos pesquisadores em estudar o potencial dos Memoriais de Formação nos cursos de licenciatura. A produção acadêmica neste campo é registrada no número de teses de doutorado, dissertações de mestrado e artigos publicados, nas últimas décadas, focalizando essa temática. Como exemplo, vale ressaltar a tese de Adriane Terezinha Sartori, defendida em 2008, na Universidade Estadual de Campinas, que teve como objetivo discutir esse gênero textual como uma ferramenta relevante na formação dos professores. Para a autora, "é possível concluir que o memorial de formação é um relevante instrumento no processo de formação do professor, especialmente por possibilitar reavaliação de experiências pessoais e profissionais" (SARTORI, 2008, p. 6). Em artigo publicado em 2011, Sartori, apesar de otimista em relação à adoção dos memoriais de formação nos cursos de licenciatura, levanta uma preocupação ligada aos limites desse gênero na formação de professores:

Não será (e não pode ser) o gênero discursivo o 'salvador' do processo formativo; afinal, ele se insere em um sistema de atividades/gêneros da esfera acadêmica, mas pode ser um importante instrumento para docentes universitários interessados em construir alternativas no árduo processo de 'formar' (bons) professores. (SARTORI, 2011, p. 15)

Demonstrando o interesse acadêmico sobre a temática da escrita de Memoriais de Formação, Maria de Fátima Pinheiro Carrilho defendeu sua tese na Universidade Federal do Rio Grande do Norte, em 2007, que teve como objetivo estudar a trajetória de formação de um grupo de professores formadores que contam as experiências de se tornarem orientadores de memoriais de formação. Conclui, em suas análises, que a função de orientador dos memoriais exige, além do aprofundamento dos saberes docentes adquiridos, outros saberes, inclusive sensibilidade e intuição. Como conclusão, Carrilho acentua que nessa trajetória,

Os professores formadores articulam o campo da experiência prática e o campo teórico-metodológico, mas essa articulação implica um novo vínculo com a sua própria humanidade, o que lhes permite dar um novo sentido às aprendizagens, habilidades para apoiar o aluno na descoberta de si mesmo e, nesse processo, descobrirem o que constitui a sua identidade de professores formadores e orientadores (CARRILHO, 2007, p. 6)

Mesmo não sendo o foco da nossa análise acompanhar o processo de elaboração dos memoriais das professoras, foi observada a forma como ocorreu o estabelecimento de um importante vínculo afetivo entre as docentes e os orientadores dos TCC, sendo considerado como de fundamental importância para o início do processo de escrita das histórias de vida narradas, tal como evidenciado na tese de Carrilho (2007).

Nesse cenário de diálogo com a produção acadêmica, destacam-se a contribuição de Maria da Conceição Passeggi e Maria Helena Abrahão, ambas com uma extensa publicação de livros e artigos, alguns em parceria 
com outros pesquisadores da área. Em texto publicado em 2008, Maria Passeggi aprofunda sua reflexão sobre o memorial, na categoria de gênero acadêmico autobiográfico, "como uma arte profissional de tecer uma figura pública em si, ao escrever sobre recortes da vida [...]" (2008, p. 27). Nessa perspectiva, a autora assinala que:

A escrita do memorial democratiza as narrativas de fatos memoráveis, substituindo o personagem ilustre, o notável, pelo narrador-autor que se coloca em cena como herói de sua própria história, inserindo sua vida intelectual no conjunto da vida científica da academia. Finalmente, a escrita do memorial populariza a autoria pela inscrição de autores não consagrados no discurso acadêmico canônico. PASSEGGI, 2008, p. 37)

Nessa direção, é no trabalho de Abrahão (2011) que encontramos uma definição do que intitulamos Memorais de Formação, neste artigo. A autora conceitua esse gênero de modo a abrigar as principais características identificadas na produção por nós analisada, visto que os memoriais são resultantes de um processo que envolve o sujeito responsável pela narrativa na condição ambígua de autor e objeto de sua reflexão. Para a referida autora, o memorial de formação é

[...] o processo e a resultante da rememoração com reflexão sobre fatos relatados, oralmente e/ou por escrito, mediante uma narrativa de vida, cuja trama (enredo) faça sentido para o sujeito da narração, com a intenção, desde que haja sempre uma intencionalidade, de clarificar e ressignificar aspectos, dimensões e momentos da própria formação (ABRAHÃO, 2011, p. 166)

Assim, a adoção dos Memoriais de Formação nos cursos de professores tem sido identificada com o próprio desenvolvimento dos currículos que se tornam afinados com uma "sensibilidade à história dos aprendentes e da sua relação com o saber", segundo Josso (2002, p. 13). Essa sensibilidade apontada pela auto- ra é percebida claramente no próprio conceito de memorial defendido por Abrahão (2011) e na repercussão democrática que subjaz a sua adoção nessas propostas curriculares de formação de professores (PASSEGGI, 2008).

Diante do exposto, observamos ser interessante aproveitar a oportunidade da crescente aceitação dos Memoriais de Formação no formato de TCC, em diversas experiências curriculares, como um campo de investigação. Os memoriais são geralmente redigidos pelos estudantes, no final do curso de graduação e/ou especialização, como um pré-requisito para a obtenção do grau acadêmico pleiteado. Neste artigo, centramos justamente na análise do trabalho final do Curso de Licenciatura especial em Pedagogia, com o objetivo de investigar as características dessa produção acadêmica, quando elaborada por professoras experientes de redes públicas de ensino, que atuam nas etapas iniciais da Educação Básica.

O nosso interesse na análise dos memoriais foi o de contribuir com as pesquisas que se debruçam sobre uma problemática presente no campo da formação de professores. Essas pesquisas focalizam os possiveis resultados nas aprendizagens dos profissionais que frequentam cursos de formação em serviço, no que se refere à identidade docente e ao aperfeiçoamento de suas práticas pedagógicas. Para tanto, selecionamos da AD o interdiscurso como dispositivo de análise, tendo em vista que é possivel rememorar a prática docente a partir do que é mobilizado nos memoriais.

Pretendemos investigar, portanto, as marcas deixadas nas narrativas autobiográficas de um grupo de docentes que cursou a Licenciatura Especial em Pedagogia, na Universidade Federal da Bahia (UFBA), no âmbito do Programa Nacional de Formação de Professores (PARFOR), entre 2010 e 2013. Com essa pretensão, procuramos perceber, em seus discursos, os aspectos considerados significativos pelas 
professoras-cursistas em um momento de fechamento de um ciclo formativo que durou três anos, entre o ingresso e a conclusão do Curso de Licenciatura.

No grupo formado por 37 professoras-estudantes, 18 concluíram o TCC na perspectiva textual de um Memorial de Formação. Todos os TCC foram analisados e, a seguir, serão evidenciadas algumas passagens relatadas pelas autoras, procurando socializar os marcos significativos dos seus percursos de formação e o tipo de articulação que elas explicitaram entre esses itinerários e os conteúdos do Curso que estavam frequentando.

A faixa etária das professoras-alunas está acima dos 35 anos, sendo que a maioria delas está situada entre 45 e 55 anos. Em relação ao tempo de atuação no magistério, registramos o mínimo de dez anos de experiência na rede pública de diferentes redes de ensino, iniciada ora como professora, ora como auxiliar de classe.

Entre as características comuns aos memoriais dessas 18 professoras, observamos a opção da escrita em primeira pessoa. De outra parte, todas evidenciaram uma descrição de passagens das Histórias de Vida selecionadas, no sentido de oferecer argumentos para a narrativa construída, procurando mostrar um elo entre alguns dos conteúdos do Curso e um novo olhar para a sua identidade profissional. Tais aspectos nos remetem à defesa de Marie-Cristine Josso, quanto à importância de se privilegiar a perspectiva dos professores nesse enfoque:

Enquanto objeto de observação, enquanto objeto pensado, a formação encarada do ponto de vista do aprendente torna-se um conceito gerador à volta do qual vêm agrupar-se, progressivamente, conceitos descritivos: processos, temporalidade, experiência, aprendizagem, conhecimento e saber-fazer, temática, tensão dialética, consciência, subjetividade, identidade. (JOSSO, 2002, p. 27-28)
Do ponto de vista das professoras, vimos esse movimento de construção de sentidos, pontuados na citação anterior, revelando o desafio da pesquisa em si. Foi preciso pensar no que foi ofertado pelo Curso, em quais condições, e quem são as professoras-autoras dessa produção. Mesmo porque esse é um pressuposto da $A D$, qual seja, o de considerar nos enunciados dos discursos produzidos pelos sujeitos socio-históricos a sua identidade. Aqui, neste artigo, foi considerada a identidade profissional do docente.

\section{Com a palavra, as professoras- alunas!}

A materialidade discursiva da produção dos TCC das professoras-alunas, que será apresentada nos fragmentos a seguir, deve ser analisada a partir do que é dito e também dos silêncios que significam e mudam a direção da interpretação dos sujeitos. (ORLANDI, 2003; 2004). A beleza identificada nas categorias que foram construídas no interdiscurso produzido pelas professoras é de uma extraordinária polifonia de sentidos e possibilidades de interpretação, conceitos explorados acerca da ação memorialista assumida por elas.

Selecionamos alguns trechos das narrativas das professoras-estudantes a partir da repetição e da regularidade identificadas nos enunciados dos discursos. Esse exercício gerou os temas valorizados pelas professoras em suas escritas. As passagens dos memoriais que revelaram de forma mais ilustrativa as subjetividades das alunas foram apresentadas, levando-se em consideração os limites deste trabalho, na medida em que elas nos provocaram a compreender o sentido de escrever suas experiências: a experiência vivida na infância durante o processo de escolarização, o significado da profissão docente e os aprendizados proporcionados pelo Curso, bem como o sentido simbólico da conclusão do Curso. 
É conveniente registrar que os temas foram abordados por todas as autoras, a partir de uma perspectiva singular e, ao mesmo tempo, contendo suas idiossincrasias em relação às reflexões do grupo de autoras, como já foi dito. Esse movimento revelou, por exemplo, que os sentidos atribuídos às possíveis lacunas existentes na formação profissional somente são identificados a partir da análise do silenciamento de uma visão mais crítica ao alcance do Curso de Pedagogia que frequentaram. Essa materialidade discursiva é percebida no conteúdo ideológico do não dito presente nos discursos analisados, indicando uma atenção atribuída aos aspectos positivos da formação, em detrimento de outras formas de interpretação desse processo.

Ao escrever seus memoriais, percebemos entre o dito e o interdito dos enunciados das professoras, ao escreverem sobre o sentido de suas próprias experiências. Assim, as docentes puderam realçar a importância de evidenciar o processo de produção do conhecimento, de formação e de exercício da profissão. Quem acompanhou de perto, percebeu como foi dificil para elas convencerem-se de que, lançar-se na aventura de escrever um memorial formativo, é constatar a coerência explicitada, por escrito, do quanto foi enriquecedor o processo pedagógico. É o que revela Bárbara Sacramento:

Para o meu trabalho de final de curso penso que esta modalidade metodológica se encaixa com o meu desejo de demonstrar o aprendizado que tive até agora no curso de Licenciatura em Pedagogia, PARFOR, atrelando às minhas memórias de início de carreira profissional com as memórias recentes, bem como a contribuição das leituras dos textos teóricos que me auxiliaram a refletir sobre a importância do brinquedo e da brincadeira para as crianças de $4 \mathrm{e}$ 5 anos, atendidas na escola em que eu trabalho. (SACRAMENTO, 2013, p. 9)

Carmen Oliveira corrobora com esse pensamento e mostra os desafios e conquistas al- cançadas através do Curso de Pedagogia. Suas reflexões versam sobre formação, condições de trabalho, valorização do magistério e os desafios enfrentados pela mulher professora na sociedade contemporânea:

É importante utilizar a história de vida no memorial porque, no ato de anotar as coisas lembradas ou de registrar partes essenciais de uma questão ou reflexão, usamos a linguagem escrita, relatamos coisas da nossa vida, o que vivemos e presenciamos. Não são histórias inventadas, relatamos tanto o presente como o passado. (OLIVEIRA, 2013a, p. 9)

0 entendimento de que os processos formadores de professores precisam ser registrados, permitiram às autoras valorizar o gênero textual escolhido para o TCC, pela descoberta do quanto estavam livres para contar suas experiências e aprendizagens significativas, como bem ilustra a afirmação de Edneide Silva:

\begin{abstract}
[...] um excelente veículo para tornar público o que fazemos - assim podemos ter as nossas histórias contadas. Isso é fundamental, porque a memória dos profissionais é pouco valorizada em nossa cultura. E há muitas histórias por contar [...] Ao narrar nossa experiência, podemos produzir no outro a compreensão daquilo que estamos fazendo e do que pensamos sobre o que fazemos (SILVA, 2013a, p. 10)
\end{abstract}

Aconstatação do quantoseautoconheceram e da necessidade de deixar por escrito essa história, é uma forma de reconhecer que esse gênero discursivo acrescentou mais elementos e descobertas ao processo formativo que estavam vivenciando no decorrer do Curso. A ação do poder transformador das descobertas autobiográficas é muito discutida por Josso (2002; 2007) e por Abrahão (2011), em suas experiências com Histórias de Vida e processos de elaboração de Memoriais de Formação. Para Josso (2002, p. 17):

[...] A originalidade do método de investigaçãoformação em Histórias de Vida situa-se, em 
primeiro lugar, na nossa constante preocupação de que os autores de narrativas consigam atingir uma produção de conhecimentos que tenha sentido para eles, que eles próprios se inscrevam num projecto de conhecimento que os institua como sujeitos. (JOSSO, 2002, p. 17)

As professoras-autoras viveram muitas das angústias relacionadas à suspeita de que não havia nada de importante para narrar de si, até o momento em que descobrem o quanto têm a dizer nesse exercício de ressignificação, no presente, de recordações do passado. Aqui, destacamos a atuação dos orientadores dos memoriais, tal como discutido por Carrilho (2007), visto que eles estimularam a ocupação de um lugar de protagonismo, por parte das professoras-cursistas, sem o qual a formação discursiva não teria encontrado respaldo para se manifestar nos escritos, apreendidos por nós na teia de significados presentes no interdiscurso produzido por elas.

As professoras, nos seus Memoriais de Formação, fazem a correlação entre $a$ experiência vivida na infância durante os primeiros anos de escolaridade e as suas vivências, no ambiente escolar, nos dias atuais, como profissionais da educação, agora em novos cenários. As recordações parecem-se com a busca de um elo de identificação entre elas e seus alunos, no sentido de explicarem, parcialmente, o interesse pelos componentes curriculares ligados à psicologia infantil e suas contribuições para uma melhor compreensão das ações pedagógicas por elas desenvolvidas.

Carmem Oliveira relata que estudou em um colégio muito organizado, cheio de regras e guarda boas recordações. Descreve a rigidez de um tempo guardado em sua memória, no qual seus professores tratavam bem os alunos e se preocupavam com a disciplina, a higiene e a boa apresentação deles, sinalizando que não identifica na escola que trabalha uma preocupação semelhante com essas questões que the fazem tão bem lembrar:
Lembro-me que nenhuma aluna poderia entrar com chinelos. Tinha que ser com sapato fechado preto ou azul. Não se aceitava alunas com fardas sujas, nem cabelos desarrumados. Tinha que fazer uma fila no início das aulas no pátio para cantar o Hino Nacional e hastear a bandeira brasileira. As alunas eram escolhidas na hora para hastearem a bandeira. Eu adorava ser escolhida. Comparando aos dias atuais, em algumas escolas não existe essa preocupação. Os alunos entram no recinto da escola até de boné, de sandálias, roupas sujas. Não se percebe o cuidado das famílias nem mesmo dos profissionais das escolas em exigir um mínimo de organização, limpeza dos seus filhos e alunos para se apresentarem na instituição escolar. (OLIVEIRA. 2013, p. 13)

Arlete Dias retrata que morou no subúrbio da cidade e seu transporte principal para chegar até a escola era o trem. Nas suas memórias, ela lembra-se de que, geralmente, perdia o trem e não chegava cedo, e que foi preciso se manter atenta e vigilante para não perder o sonho de estudar que tinha desde criança:

Uma imagem não me sai da mente: Ogum, eu e o trem. Vivo sempre atenta e operante para não perder o trem de vista. Já não há mais tempo para perdê-lo [...] Para mim, esse elemento me remete a doces e tristes lembranças. A boa recordação se dá em face da linha, significando continuidade, ciclo, pessoas que iam e vinham representando a vida, a passagem. Mas outras me entristeciam: quando eu subia e descia incontáveis ladeiras em meio à lama para o meu percurso escolar, avistava o trem, corria desesperadamente, e o via fechar as suas portas pra mim, sem se despedir, distanciando-se das minhas expectativas quanto à escola que se tornava cada vez mais distante de mim [...] 0 trem quase sempre me deixava pra trás. Eu insistentemente o encontraria em outras estações. Sonhava com outras primaveras, planejava outros verões. (DIAS, 2013, p. 19)

As recordações da infância foram interpretadas como pretextos para justificar as mudanças na forma de pensar e agir em relação à infância que elas acessam hoje nas escolas 
em que atuam, na condição de professoras. No TCC, elas justificam a rigidez ou a ênfase em descobrir formas mais lúdicas de lidar com as crianças, no cotidiano de suas salas de aula, nas escolas em que lecionam, porque conseguiram desenvolver uma "consciência" de que as crianças vivem outra lógica e que os adultos precisam compreendê-la, para conseguir dialogar com elas e ter sucesso nas intervenções pedagógicas propostas.

Assim, consideramos que houve um espaço privilegiado de exploração da revisita ao passado, como uma atualização das memórias devido à necessidade de, como profissionais da educação, refletirem sobre o seu fazer docente, procurando novos sentidos e desafios para si. o processo de atualização deflagrado advém da formação ideológica dos enunciados, outro dispositivo da $A D$ que nos ajuda a perceber a rebeldia em relação ao tempo cronológico, uma característica da memória discursiva, como bem define Pêcheux (1999).

Ainda no percurso desses Memoriais de Formação, foi possivel identificar as dificuldades emocionais evidenciadas pelas professoras, na medida em que suas experiências iniciais como alunas iam emergindo, em uma tentativa de registrar o esforço de superar obstáculos durante a formação. Nesse sentido, descobrimos um olhar para os processos que elas vivenciaram, especialmente as dores e os preconceitos vividos em suas práticas, quando ainda alunas da educação básica, conforme ilustram os trechos a seguir, à luz de temas que as professoras-autoras mostraram grande interesse em aprender, no decorrer do Curso de Pedagogia.

Nas atividades escritas tinha muito sucesso, mas nas atividades orais, que eu tinha que me expressar eu sentia muita dificuldade, chorava muito na hora que eu tinha que me apresentar por isso tantos professores, quanto os meus colegas não faziam questão da minha participação nesses tipos de atividades, dessa forma me sentia bastante excluída, penso que essa deficiência deveria ser trabalhada desde a Educação Infantil. Portanto, não só a ausência do cuidado, mas também o fazer pedagógico de alguns professores marcou de forma negativamente a minha vida tanto naquela época, como nos dias atuais, refletindo na maneira de me expressar publicamente. (SILVA. 2013a, p. 7)

Tais sentimentos puderam ser explicitados através da escrita-reflexão. A professora Telma Pereira, por exemplo, revelou que a escrita do TCC ressignificou os efeitos dos preconceitos raciais sentidos na infância. Ela conta que foi uma criança negra e pobre, mas é essa identidade e o pertencimento daquela menina que the inspiram a busca de um sentido ainda maior no trabalho que desenvolve, como professora consciente da diversidade étnico -racial, com as crianças que convivem, ainda hoje, com os efeitos adversos de uma sociedade racista, cuja perversidade sentiu na pele e marcou a sua história de vida:

Exercitar a lembrança significa rememorar muitas questões que ainda são dolorosas de lembrar. No entanto, acredito na pertinência desse instrumento, o memorial, visto que possibilitou refletir sobre o lugar do negro na educação brasileira e o meu lugar como mulher, negra e educadora na Educação Infantil. Esse trabalho é importante para mim porque permite uma mudança interior. Antes, eu só pensava em reagir da mesma forma que a sociedade racista tinha agido comigo, mas hoje eu sei que nós devemos respeitar a diversidade de crenças e outras diversidades também. Hoje eu vejo com mais clareza a importância do respeito à criança em suas diversas expressões. E isso é uma forma de me sentir melhor comigo mesma. (PEREIRA, 2013, p. 8)

Carmem Oliveira, com o seu jeito humorado, relata constrangimentos vividos como estudante. Por ser alta e magra, era alvo das brincadeiras dos seus colegas, o que a fazia tímida e reservada. Refletindo sobre isso, escreveu que hoje tem conhecimento de que tais 
práticas não podem ser vistas por uma docente de forma naturalizada, pois elas podem ter efeitos ainda mais negativos em outras crianças e jovens:

Eu tinha vergonha do meu corpo, porque sou muito alta e era muito magra. Sempre a maior da sala. Eu sofri muito com os apelidos que as colegas colocavam em mim: Olivia Palito, Espelho Sem Aço, Graveto e outros. Minha mãe fazia tranças compridas no meu cabelo e as colegas ficavam esticando. Eu não fazia nada, ficava na última cadeira da sala para não ser incomodada. Se eu sentasse nas carteiras da frente as colegas gritavam: Sai da frente, espelho! Agora eu sei que essas ações que as minhas colegas faziam são denominadas de Bulling. Uma palavra nova que estudamos nas disciplinas do curso de Pedagogia, como em Psicologia da Aprendizagem, no primeiro semestre e neste último semestre, na disciplina Psicologia das Relações Humanas. (OLIVEIRA, 2013, p. 14)

Os primeiros passos na docência levou, na visão das autoras, ao amadurecimento pessoal, já que as responsabilidades da profissão foram percebidas com muita força pelo fato de serem jovens, pois não é dificil encontrar depoimentos do quanto elas se sentiam respeitadas pelos alunos, mesmo não tendo muita idade. Sobre a importância dos conteúdos aprendidos no Curso de Pedagogia, muitos são os enunciados que revelam a força da formação discursiva, mais um dispositivo da AD, pelo fato de terem se apropriado do ambiente da academia, na condição de professoras-estudantes, o que as faz narrar o prazer que sentem em levar na "bagagem" as concepções teóricas dos diversos campos do saber dos quais se aproximaram.

As professoras demonstram as razões que as fizeram escolher a carreira do magistério e o desejo expresso em avançar em seus percursos formativos, em busca de maior qualificação profissional. Ao focalizar o significado da profissão docente $e$ as "lições aprendidas no curso", razões pessoais, familiares e a fal- ta de outras oportunidades marcam a decisão de tornarem-se professoras. Rita Santos, por exemplo, revive o quanto foi acertada a sua decisão:

Entrei no ensino médio com uma certeza: vou cursar o magistério. [...] logo que terminei o curso, participei de um concurso público para professora oferecido pela Prefeitura Municipal do Salvador, no qual fui aprovada. Ao saber do resultado, fiquei bastante feliz e ansiosa para poder desenvolver essa atividade que sempre foi o meu desejo [...]. (SANTOS, 2013c, p. 11)

No caso de Maria Gonçalves, ser professora é motivo de orgulho e agradecimento ao esforço do seu pai, pois foi ele quem definiu o magistério como carreira para as filhas:

Foi assim que cresci ouvindo esses planos do meu pai [...]. Apesar de meus pais não serem alfabetizados, admiravam uma boa leitura! Tinham apreço por pessoas com essa habilidade, pois tinha referências, as irmãs do meu pai que sabiam ler e algumas sobrinhas já estudavam para professora, formadas em Jacobina, ele se orgulhava disso e nas férias de minhas primas, levava a minha irmã mais velha para compartilhar desse ambiente fértil e que ele considerava intelectual e cultural. (GONÇALVES, 2013, p.12)

Tais relatos configuram-se como uma oportunidade para pensar no quanto elas desejam saber mais para desempenhar com melhor qualidade a profissão docente, uma vez que nos memoriais fica evidente o quanto as professoras queriam continuar seu processo formativo, procurando associar a "teoria" e a "prática", após identificar-se em diferentes momentos, a depender das Histórias de Vida de cada uma, com o magistério, como nos revela Barbara Santana:

Às vezes também penso no meu trabalho ao longo desses anos, percebo a importância das teorias. Hoje sei que elas são alimentadoras da experiência e vice-versa. É muito legal você participar de cursos e ver que aquilo que você aprendeu e está estudando, se aprofundando, 
não é um assunto tão distante, que ele faz parte do seu repertório também. (SANTANA, 2013, p. 28)

Nesse processo de ressignificação encontrado nas narrativas das professoras, constatamos um interesse crescente em ensinar conteúdos mais coerentes com os novos aprendizados construídos, a partir da experiência no chão da sala de aula e dos conteúdos vistos na Universidade, como as autoras Edilânia Carmo e Maria Brito revelam:

A Universidade mudou isso na minha vida e me tornou mais sensivel e preocupada com a forma que devo ensinar e no que este ensino vai proporcionar de impacto à vida desse ser humano. Hoje visualizo um novo horizonte no mundo do ensino-aprendizagem. Conhecer, participar e me envolver com as novidades e mudanças que tangem a Educação, foi pra mim a grande oportunidade de mudança que por mim era esperada. E também por minha escola. (CARMO, 2013, p. 16-17)

Utilizo novos meios de passar os conteúdos aos alunos para que eles entendam melhor e aprendam a ler. Faço exercícios com eles, lendo devagarinho as palavras, escrevendo com eles as palavras faladas e as frases, de maneira que eles vejam a correspondência entre o que se fala e o que está escrito. Aprendi isto com as aulas de Língua Portuguesa no Ensino Fundamental e Alfabetização e Letramento. Outro recurso tem sido a utilização de material ilustrativo, conforme as professoras mostraram nas aulas. Eu já usava recortes de jornais e revistas. Agora aprendi a usar outros materiais. (BRITO, 2013, p. 30)

Quando as autoras se revelam nos memoriais, verificamos um processo em curso, no qual a Universidade é parte dele, porque as professoras evidenciam que já sentiam uma inclinação para um trabalho mais sensivel e humano e também mostram que já realizavam esforços no sentido de ajudar os seus alunos a se alfabetizarem, enquanto o Curso trazia conteúdos que as estimulavam ainda mais a continuar nessa caminhada. São as professo- ras o ponto de partida, e não a Universidade, revelando toda a riqueza do que é defendido por autores que nos motivam a pesquisar os processos de aprendizagem e a apropriação de saberes através da escrita autobiográfica (SOUZA, 2007; 2011).

Escrever sobre si, sobre sua experiência de vida e seu ambiente de atuação profissional mobiliza, certamente, o território da valorização da subjetividade e das experiências únicas de cada pessoa. E é a partir dessas rememorações que se torna possivel rever-se criticamente em situações de ensino e aprendizagem:

Com isso eu fui mudando a minha prática em sala de aula. Com esta experiência de minha formação, fui entendendo a necessidade de colocar os alunos para se expressarem, para quando chegarem ao curso superior não terem dificuldades, como eu estava sentindo. Como eu estava ensinando uma turma do 5 o ano com alunos que gostavam muito de conversar, eu fui dando mais oportunidade para que eles se expressassem na sala de aula, fazendo seminários, apresentação de teatro, dramatizações, contação de história em voz alta, etc. (OLIVEIRA, 2013a, p. 27)

As recordações entrecruzam-se com a satisfação, mais adiante discutida, de cursarem Pedagogia e de terem a oportunidade de tornarem-se professoras melhor preparadas para enfrentar os desafios da profissão, como elas dizem nos memoriais, mostrando-se muito afinadas com a identidade profissional que vão seguir até a aposentadoria.

Os discursos analisados nas narrativas das professoras sobre o quanto valorizam a proximidade do momento de conclusão do Curso reafirmam os achados de uma pesquisa de doutorado que discutiu o valor simbólico do diploma de Pedagogia, com este grupo de docentes, mostrando o quanto a Pedagogia é valorizada por essas professoras, após concluírem o Curso (JESUS, 2014). 
Essa perspectiva, evidenciada nas análises aqui descritas e encontradas no trabalho de pesquisa anteriormente citado, revela um novo olhar para a Pedagogia, dado que, comumente, ela é vista como um lócus de crise e pouco prestígio em relação a outras escolhas profissionais, e não é dessa maneira que as autoras dos memoriais apresentam esse contato que tiveram com os conteúdos da Pedagogia, tampouco com a profissionalização do Curso em si. Para as professoras, a proximidade da conclusão do curso remonta o quanto aprenderam e se motivaram com as descobertas que fizeram acerca de como trabalham.

Arlete Dias (2013, p. 22), em seu texto, afirma o significado da realização do Curso, pois recorda que sempre alimentou o sonho de rever as suas práticas docentes desde que fez o curso do magistério em nível médio. Queria conhecer, como ela diz, os "grandes teóricos", pesquisadores renomados e ter consciência do exercício da sua profissão por meio de um maior conhecimento sobre o que é dito no plano acadêmico. As demais professoras também reportam, em suas narrativas, ao significado simbólico da conclusão de um curso superior.

Outro aspecto importante, a ser ressaltado na escrita desses memoriais, diz respeito à significação conferida à qualificação docente numa perspectiva continuada, revelando o desejo e a consciência das profissionais com a implicação política de seu fazer, como é ressaltado num dos trabalhos que discute o papel das políticas públicas para a valorização dos profissionais de educação:

[...] considerando a profissão docente como um desafio permanente - apesar de termos tarefas definidas como ensinar, instruir e formar continua sendo uma profissão em permanente construção, desafiando o professor a estudar, pesquisar, aprender e tentar compreender 0 ser humano e a sociedade em geral. Portanto, proporcionar um ensino de qualidade é o mais importante. Que saibamos sempre valorizar a nossa tarefa, reconhecendo-nos como um profissional da educação em busca de constante formação e aprimoramento. [...] Uma vez que se faz necessário um professor que saiba ensinar e saiba também aprender [...]. (SANTANA, 2013, p. 18)

A importância da qualificação e requalificação dos fazeres dessas professoras configurase como uma ação política e cultural que resulta na construção de uma memória social e, consequentemente, de identidades coletivas, em razão de que advém de uma necessidade adquirida na relação com a teoria, articulada com o exercício da prática e da memória. Esse é um processo de construção que abarca pessoas, sentimentos e vida, como afirma Laura Almeida,

[...] tenho a consciência de que o meu comprometimento com a educação aumentou por uma questão de ética profissional. Necessito oferecer a minha parcela de contribuição para uma educação de qualidade, mesmo enfrentando obstáculos trazidos pelas vicissitudes pelas quais passa o sistema educativo. Com muito mais confiança e segurança, devido ao aprendizado que obtive durante a minha formação na faculdade, desejo contribuir na formação de sujeitos críticos, conscientes dos seus direitos, o que é uma grande responsabilidade, a qual pretendo honrar com empenho dentro da minha profissão. (ALMEIDA, 2013, p. 29)

Apesar de verificar a presença de uma noção de trajetória bem-sucedida, observada frequentemente na produção do gênero História de Vida (JOSSO, 2002), destacamos, na análise, os conteúdos que foram mobilizados pelas autoras dos memoriais para contar a compreensão de como se tornaram professoras mais engajadas com a profissão:

É importante entender o que já é consenso, que o magistério e a profissão professor caracterizam-se como uma atividade com diversos níveis de complexidade, exigindo revisão e construção constantes de saberes, centrando seu saber ser e saber fazer numa prática reflexiva e 
investigativa do trabalho educativo e escolar no cotidiano pessoal e profissional. (SOUZA, 2011, p. 215)

Salta aos olhos, durante a leitura e a análise dos TCC, a compreensão presente nas professoras do quanto elas consideram-se mais seguras e preparadas para dar conta dos desafios e da complexidade da atividade docente. Elas mostram não uma história pronta e acabada em relação à construção de uma identidade profissional, bem como ao aperfeiçoamento das práticas pedagógicas, mas evidenciam que estão atentas às dinâmicas presentes no ser professor, o que confere uma necessidade permanente de aperfeiçoamento, compromisso e dedicação ao longo da carreira docente.

\section{Considerações}

Os Memoriais de Formação das professoras revelaram resultados positivos da experiência formativa que vivenciaram. Demonstram, também, o grande potencial que elas guardam em suas produções textuais, quanto à apropriação de uma reflexão sobre a sua história de vida e as transformações ocorridas durante as novas aprendizagens a que tiveram acesso, tendo como foco as atividades de formação dos três anos do Curso.

Constituiu-se em um exercício de aprendizagem, criatividade e fortalecimento da identidade profissional relacionar os conteúdos do Curso com a apropriação de uma escrita autoral, na primeira pessoa, visto que, nesse gênero, elas precisaram superar a ideia de que se pode narrar uma caminhada pouco conhecida de acesso a conteúdos intrinsecamente interligados ao fazer docente, levando-as a uma as- sociação entre a teoria e a prática baseadas na experiência diante do processo formativo, que deixaram claro não ter fim.

As reflexões a respeito do processo de construção do conhecimento sobre as lições que podem ser aprendidas, a partir dos conteúdos teóricos referenciados nas práticas cotidianas do processo de ensino, levando em conta as múltiplas experiências acumuladas pelas professoras envolvidas, tem atestado a pertinência de se lutar por uma política de formação que aproxime cada vez mais os conteúdos acadêmicos das reflexões sobre as Histórias de Vida das professoras, mesmo compreendendo que há outras questões que precisam ser discutidas, quando o assunto é a melhoria dos currículos dos cursos de formação de professores.

Podemos inferir que, embora exista um grande caminho a percorrer no aprimoramento dos programas de formação de professores da Educação Básica, de algum modo sinalizamos as vantagens de lançar mão dos Memoriais de Formação, posto que eles se mostram estimulantes para a continuidade de propostas curriculares enriquecidas pela possibilidade de uma produção escrita reflexiva, autoral e carregada de sentidos para a identidade profissional das professoras.

Finalmente, consideramos ser importante investigar com mais profundidade o fenômeno do prestígio da Pedagogia, tendo em vista que se pode participar de um debate sobre como tornar possivel um casamento entre as "Ciências da Educação" e os professores de "carne e osso", em que ambos sejam valorizados e implicados a uma formação que repercuta em uma melhor qualidade do processo de ensino -aprendizagem nas escolas.

\section{Referências}

ABRAHÃO, Maria Helena M. B. Memoriais de formação: a (re)significação das imagens-lembranças/

recordações-referências para a pedagoga em formação. Educação, Porto Alegre, v. 34, n. 2, p. 165-172, 
mai./ago. 2011.

BENJAMIN, Walter. O narrador: considerações sobre a obra de Nikolai Leskov. In: Magia e técnica, arte e política: ensaios sobre literatura e história da cultura. 7 edição, Tradução de Sérgio Paulo Rouanet. São Paulo: Brasiliense, 1994. p. 213-240.

BRASIL. DECRETO n. 6.755, que Institui a Política Nacional de Formação dos Profissionais da Educação Básica (PARFOR), Brasília, 29 de janeiro de 2009. Disponivel em: http://www.capes.gov.br/images/ stories/download/legislacao/Decreto-6755-2009. pdf Acesso em: 05 ago. 2017).

CARRILHO, Maria de Fátima Pinheiro. Tornar-se professor formador pela experiência formadora: vivências e escrita de si. 2007. 275 p. Tese (Doutorado em Educação Educação) - Programa de Pós-graduação em Educação, Universidade Federal do Rio Grande do Norte, Natal, 2007. Disponível em: <https:// repositorio.ufrn.br/jspui/handle/123456789/14532>. Acesso em: 24 jul. 2017.

JESUS, Marta Lícia Teles Brito. O valor simbólico do diploma de nível superior. 2014. 227 p. Tese (Doutorado em Educação) - Programa de Pós-graduação em Educação, Universidade Federal da Bahia, Salvador, 2014.

JOSSO, Marie-Christine. Experiências de vida e formação. Lisboa: Editora Educa-Formação/Universidade de Lisboa, 2002.

A transformação de si a partir da narração de histórias de vida. Educação, Porto Alegre, n. 3 (63), p. 413-438, set./dez. 2007.

KOFES, Suely. Narrativas biográficas: que tipo de antropologia isso pode ser? In: KOFES, Suely; MANICA, Daniela. (Orgs.). Vida \& grafias: narrativas antropológicas entre biografia e etnografia. Rio de Janeiro: Editoras Lamparina: FAPERJ, 2015. p. 20-40.

LE GOFF, Jacques. História e memória: II volume . Tradução de Bernardo Leitão. Lisboa: Edições 70, 2000.

LOBATO, Monteiro. Emília resolve escrever suas memórias. In: Memórias de Emília. São

Paulo: Brasiliense, 1995. cap. 10, p. 9-13.
ORLANDI, E. P. As formas de silêncio: nos movimentos dos sentidos. 5. ed. Campinas: Editora da UNICAMP, 2002.

Análise de discurso: princípios e procedimentos. 5. ed. Campinas, SP: Pontes, 2003.

Interpretação: autoria, leitura e efeitos do trabalho simbólico. 4. ed. Campinas: Pontes, 2004.

PASSEGGI, Maria da Conceição. Memoriais autobiográficos: a arte profissional de tecer uma figura pública de si. In: PASSEGGI, Maria da Conceição; BARBOSA, Tatyana Mabel Nobre. (Orgs.). Memórias, memoriais: pesquisa e formação docente. Natal: EDUFRN; São Paulo: Paulus, 2008. p. 27-42.

PÊCHEUX, Michel. Papel da memória. In: ACHARD, P et al. Papel da memória. Campinas, SP: Pontes, 1999. p. 49-57.

POLLAK, Michael. Memória e identidade social. Estudos Históricos, Rio de Janeiro, v. 5, n. 10, p. 200212, 1992.

SARTORI, Adriane Terezinha. Os professores e sua escrita: o gênero discursivo "memorial de formação". 2008. 219 p. Tese (Doutorado em Linguística Aplicada) - Programa de Pós Graduação do Instituto de Estudos da Linguagem, Universidade Estadual de Campinas, Campinas, SP, 2008. Disponível em: <http:/ / libdigi.unicamp.br/document/?code=vtls000440323>. Acesso em: 25 jul. 2017.

O memorial de formação e a graduação de (futuros) professores. Revista SCRIPTA, v. 15, n. 28, p. 267-284, PUC Minas Gerais, 2011. Disponível em: <http://periodicos.pucminas.br/index.php/scripta/ article/view/4319>. Acesso em: 25 jul. 2017.

SOUZA, E. C. (Auto)biografia, histórias de vida e práticas de formação. In: NASCIMENTO, Antonio Dias; HETKOWSKI, Tania Maria. (Orgs.). Memória e formação de professores. Salvador: EDUFBA, 2007. p. 137156.

- Territórios das escritas do eu: pensar a profissão - narrar a vida. Educação, Porto Alegre, v. 34, n. 2, p. 213-220, mai./ago. 2011. 


\section{Fontes}

ALMEIDA, Laura Maria Contreiras de. Reflexos das reformas educacionais na formação de uma professora. Trabalho de Conclusão de Curso Salvador. Universidade Federal da Bahia. Curso Licenciatura em Pedagogia - PARFOR. Faculdade de Educação. 2013.

BRITO, Maria da Paz Soares de. Da alfabetização de jovens e adultos ao curso de pedagogia. Trabalho de Conclusão de Curso Salvador. Universidade Federal da Bahia. Curso Licenciatura em Pedagogia PARFOR. Faculdade de Educação. 2013.

CARMO, Edilania Alves da Silva do. Pedagogia do afeto: Reflexões acerca de uma prática possível em sala de aula. Trabalho de Conclusão de Curso. Salvador. Universidade Federal da Bahia. Curso Licenciatura em Pedagogia - PARFOR. Faculdade de Educação. 2013.

DIAS, Arlete Santos. Caminhos traçados: por uma pedagogia construída dia a dia. Trabalho de Conclusão de Curso. Salvador. Universidade Federal da Bahia. Curso Licenciatura em Pedagogia - PARFOR. Faculdade de Educação. 2013.

GONÇALVES, Maria Das Graças Lima. A literatura de cordel na formação de crianças leitoras. Trabalho de Conclusão de Curso. Salvador. Universidade Federal da Bahia. Curso Licenciatura em Pedagogia PARFOR. Faculdade de Educação. 2013.

MELO, Dejanira Rainha Santos. Planejamento e avaliação: uma trajetória pela busca de fazer melhor. Trabalho de Conclusão de Curso. Salvador. Universidade Federal da Bahia. Curso Licenciatura em Pedagogia - PARFOR. Faculdade de Educação. 2013.

OLIVEIRA, Carmem Lucia. Meu percurso acadêmico: tecendo considerações sobre formação e valorização do professor da educação básica. Trabalho de Conclusão de Curso Salvador. Universidade Federal da Bahia. Curso Licenciatura em Pedagogia - PARFOR. Faculdade de Educação. 2013.

OLIVEIRA, Maria do Carmo de. A aprendizagem como um processo: aproximações teóricas e práticas do meu percurso acadêmico. Trabalho de Conclusão de Curso. Salvador. Universidade Federal da Bahia.
Curso Licenciatura em Pedagogia - PARFOR. Faculdade de Educação. 2013a.

OLIVEIRA, Mariana de Assis. O papel do professor no enfrentamento do bullying no contexto escolar. Trabalho de Conclusão de Curso. Salvador. Universidade Federal da Bahia. Curso Licenciatura em Pedagogia - PARFOR. Faculdade de Educação. 2013b.

PEREIRA, Telma Regina Gusmão. Desfazendo a dor: Relatos de discriminação e superação de negros na educação. Trabalho de Conclusão de Curso. Salvador. Universidade Federal da Bahia. Curso Licenciatura em Pedagogia - PARFOR. Faculdade de Educação. 2013.

SACRAMENTO, Barbara Cristina. O brinquedo e a brincadeira na educação infantil: a vivência lúdica no espaço escolar. Trabalho de Conclusão de Curso. Salvador. Universidade Federal da Bahia. Curso Licenciatura em Pedagogia - PARFOR. Faculdade de Educação. 2013.

SANTANA, Bárbara Cristina Santos. Caminhos percorridos para a formação de uma carreira docente. Trabalho de Conclusão de Curso. Salvador. Universidade Federal da Bahia. Curso Licenciatura em Pedagogia - PARFOR. Faculdade de Educação. 2013.

SANTOS, Aidil Neves Aleluia dos. A importância das histórias e contos na educação infantil e o meu percurso acadêmico. Trabalho de Conclusão de Curso. Salvador. Universidade Federal da Bahia. Curso Licenciatura em Pedagogia - PARFOR. Faculdade de Educação. 2013.

SILVA, Cristiane Alves da Hora Nascimento. Educar e cuidar na creche: dimensões complementares indissociáveis na educação de crianças de 0 a 3 anos. Trabalho de Conclusão de Curso. Salvador. Universidade Federal da Bahia. Curso Licenciatura em Pedagogia - PARFOR. Faculdade de Educação. 2013.

SILVA, Edneide do Nascimento Oliveira da. Práticas de leitura e escrita na educação infantil: reflexões a partir de uma experiência no CEIMI de Itaparica. Trabalho de Conclusão de Curso. Salvador. Universidade Federal da Bahia. Curso Licenciatura em Pedagogia - PARFOR. Faculdade de Educação. 2013a.

SILVA, Gleide Mota da. Reflexões sobre letramento 
no grupo V da educação infantil. Trabalho de Con-

clusão de Curso. Salvador. Universidade Federal da Bahia. Curso Licenciatura em Pedagogia - PARFOR. Faculdade de Educação. 2013b.

SANTOS, Rita de Cassia Pereira dos. Família e escola: construindo laços e compromissos. Trabalho de Conclusão de Curso. Salvador. Universidade Federal da Bahia. Curso Licenciatura em Pedagogia - PARFOR. Faculdade de Educação. 2013c.
SOUSA, Lucinéia Santos. Da experiência de ler, contar e escrever histórias: relatos de vivências em turmas de educação infantil. Trabalho de Conclusão de Curso. Salvador. Universidade Federal da Bahia. Curso Licenciatura em Pedagogia - PARFOR. Faculdade de Educação. 2013.

Recebido em: 22.02.2017

Aprovado em: 23.07.2017

Maria Couto Cunha é licenciada em Ciências Sociais, Mestre e Doutora em Educação - UFBA. Professora do Programa de Pós-Graduação em Educação da Faculdade de Educação - UFBA. Coordenadora da Linha de Pesquisa Política e Gestão da UFBA. e-mail: mariacoutocunha@gmail.com

Rua Barão de Loreto, n. 96. Apto 401, Graça, Salvador - Bahia, CEP 40150-270

Telefone: (71) 988583937

Marta Lícia Brito de Jesus é Mestre e Doutora em Educação-UFBA. Professora do Departamento I da Faculdade de Educação - UFBA. Tutora do Programa de Educação Tutorial - PET. Participante da Linha de Pesquisa Política e Gestão UFBA e da Linha de Pesquisa Educação Sociedade e Cultura - UFRB. e-mail: martaliciatelesbr@yahoo.com.br

Alameda do Bosque, 836, Cond. Reserva das Árvores, Edf. Jacarandá, apto 1701, Horto Bela Vista, Salvador - Bahia. CEP: 41098-010

Telefone: (71) 987880674

Regina Lucia Portela é Mestre em Artes Cênicas UFBA. Mestranda do Programa de Pós-graduação em Educação da Faculdade de Educação UFBA. Participante da Linha de Pesquisa Política e Gestão - UFBA. e-mail: regina.portela@yahoo. com.br

Rua Bernardo Catarino, 101, Casa - Barra Avenida, Cep: 40130-040, Salvador - Bahia, CEP 40130-140-040

Telefone: (71) 98809-4622 